\section{Tech Yourself Fluid Concepts: How to Use Internet Resources}

\author{
S. Viridi*, F. Haryanto, F. A. Purnama
}

Department of Physics, Institut Teknologi Bandung

Jalan Ganesha 10, Bandung 40132, Indonesia

*dudung@gmail.com | https://dudung.github.io

\section{VERSION 20171031.9}

It is interesting to find out that students still have difficulties in learning ideal fluids at the introductory level in the first year university courses, especially for hydrodynamics concept (Suarez et al. 2017), even there is already a lot of resources related to fluids topics for elementary physics (and of course beyond it) in the forms of not-so-easy-old-textbooks-to-read for hydrostatics (Loney 1992) and hydrodynamics (Chirgwin \& Plumpton, 1967), today lecture note with a lot of figures and motivations (McDonough, 2009), formal lecturer video (YaleCourses, 2008), free online course videos (KhanAcademy, 2017), commercial courses teaching video with 5-day free trials (Friedl, 2017), lecture slides and homework (Bolster, 2013), concept map (Nave, 2017), and encyclopedia article (Faber, 2016).

One of the problems for students while searching in the web is impulsiveness, that they tend to find immediately an exact right answer instead of first collecting piece by piece information in constructing the one (Kuiper et al., 2008). There is a lot of search engines can be used to search information in the web (Gil, 2017), and even we can search how to search (Gibbs, 2016). Resources in the previous paragraph, which are related to fluid concepts, have been found using the following search terms together: fluids, concepts, pdf, elementary physics, online course, etc.

In an Elementary Physics course the topics could be as starting search terms, e.g. density, volume, fluid flow rate, continuity equation, hydrostatic pressure, fluid pressure, Bernoulli's principle, Archimedes' principle, u pipe hydrostatics, surface tension, etc. Even Wikipedia is not suggested as primary source for information we can still use it as a start point, since its content is more comprehensive than results of a search engine.

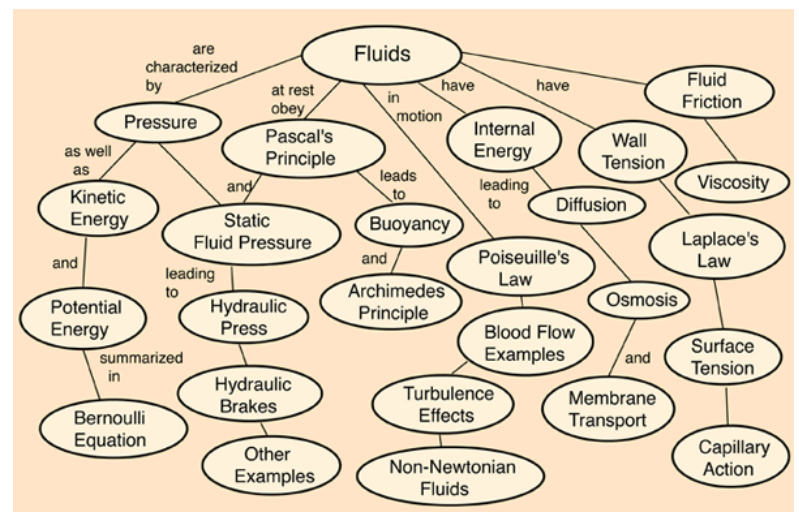

Figure 1. Map concept of fluids in HyperPhysics (Nave, 2017).

Supposed that we would like to learn about something related to fluids but we do not know in which part it should be. Then we can first navigate to the work of
Nave in HyperPhysics (Nave, 2017) for the concept map as shown in Figure 1. Assumed from the map it was Archimedes principle. Then, we can search the term in the web.
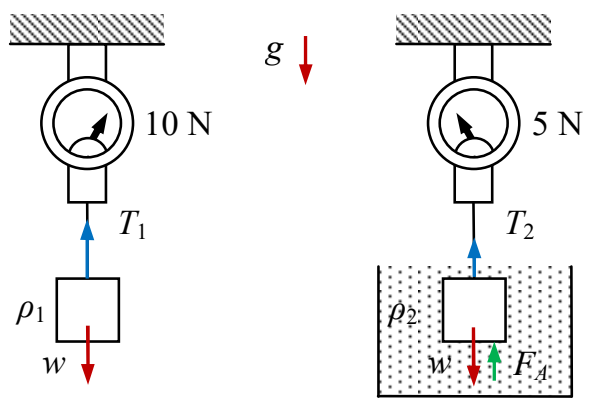

Figure 2. Measuring weight of a mass: in air (left) and in fluid with density $\rho_{2}$ (right).

Example of a problem is given in Figure 2, where value of $g, T_{1}, \rho_{1}, T_{2}$ are known and value of $\rho_{2}$ is to find. Can we get the answer for such a particular problem in the web? With the keywords: apparent weight buoyancy fluid density, second result shows a video related to the problem at about time 7:53 (KeysToMaths1, 2013) as shown in Figure 3.

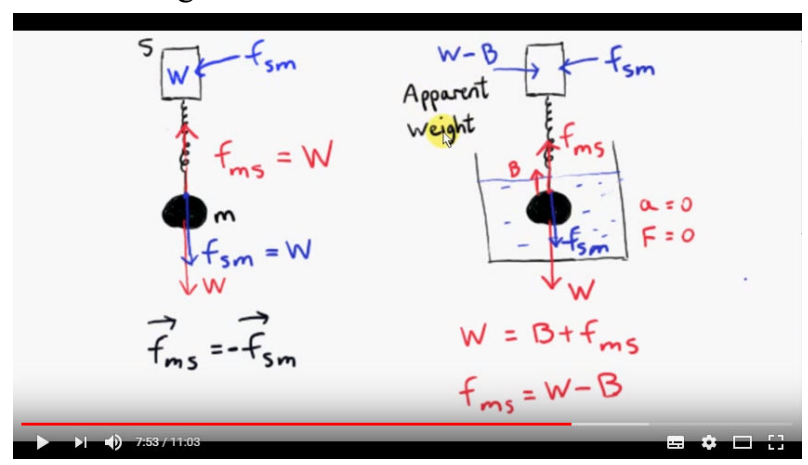

Figure 3. Measuring weight of a mass: in air (left) and in fluid with density $\rho_{2}$ (right) from (KeysToMaths 1, 2013).

It seems what given in Figure 3 is not the exact right answer and students should you the information to get the demanded solution.

In the first weight measuring it can be written that

$$
\begin{aligned}
& \sum F_{y}=0 \\
& \Rightarrow T_{1}-w=0 \\
& T_{1}=w,
\end{aligned}
$$

and from the second

$$
\begin{aligned}
& \sum F_{y}=0 \\
& \Rightarrow T_{2}-w+F_{A}=0 \\
& F_{A}=w-T_{2} .
\end{aligned}
$$

Relation among $g, w, \rho$, and $V$ will give

$$
w=m g=\rho_{1} V g
$$

and buoyant force

$$
F_{A}=\rho_{2} g V .
$$

Substitute Equation (1) into Equation (2) will produce

$$
F_{A}=T_{1}-T_{2} .
$$

Substitute Equation (4) into Equation (5) will lead to

$$
\rho_{2} g V=T_{1}-T_{2} \text {. }
$$


And finally, substitute Equation (3) to Equation (6) will give

$$
\begin{aligned}
& \left(\frac{\rho_{2}}{\rho_{1}}\right) T_{1}=T_{1}-T_{2} \\
& \Rightarrow \rho_{2}=\rho_{1}\left(1-\frac{T_{2}}{T_{1}}\right),
\end{aligned}
$$

the relation that was asked.

Please notice that the symbols used in Figure 3 are $f_{s m}$ (left), $B, f_{s m}$ (right) while in this work (Figure 2) those are $T_{1}, F_{A}$, and $T_{2}$.

Is there any other possibility for resources in the web for the same problem? The answer is yes. Figure 4 shows the alternative one at time 4:46 (van Biezen, 2016).

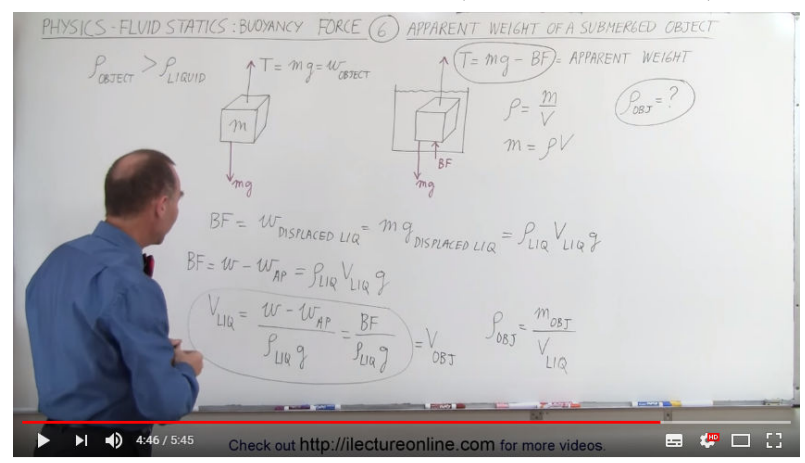

Figure 4. Measuring weight of a mass: in air (left) and in fluid with density $\rho_{2}$ (right) from (van Biezen, 2016).

Again in this video different symbols are used e.g $\rho_{\mathrm{OBJ}}$, $\rho_{\text {LIQ }}, \mathrm{BF}, T$ (left), and $T$ (right) for $\rho_{1}, \rho_{2}, F_{A}, T_{1}$, and $T_{2}$. Comparison of the uses of symbols is given in Table 1 .

Table 1. Meaning of symbols.

\begin{tabular}{lccc}
\hline \multirow{2}{*}{ Physical property } & \multicolumn{3}{c}{ Figure } \\
\cline { 2 - 4 } & 2 & $3 *$ & $4 * *$ \\
\hline Measured weight in air & $T_{1}$ & $f_{s m}$ & $T$ \\
Measured weight in fluid & $T_{2}$ & $f_{s m}$ & $T$ \\
Object density & $\rho_{1}$ & - & $\rho_{\text {OBJ }}$ \\
Fluid density & $\rho_{2}$ & - & $\rho_{\text {LIQ }}$ \\
Buoyant force & $F_{\mathrm{A}}$ & $B$ & $\mathrm{BF}$ \\
\hline \multirow{2}{*}{$*\left(\right.$ KeysToMaths1, 2013), ${ }^{* *}(\operatorname{van}$ Biezen, 2016) }
\end{tabular}

You can find as many alternatives as you want, which depend only on the keywords fed to the search engine.

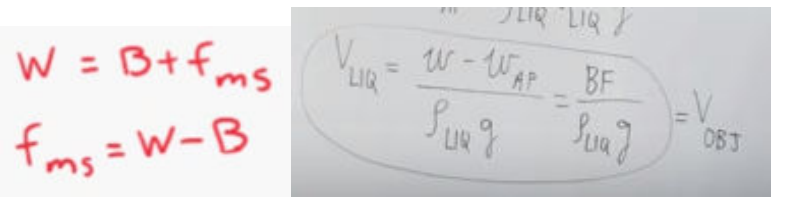

Figure 5. Comparison of formula: left (KeysToMaths1, 2013) and right (van Biezen, 2016).

We can see from Figure 5 that second resource (van Biezen, 2016) give nearer formulation to Equation (7) than the first one (KeysToMaths1, 2013). Previous work is, of course, more direct to the solution but still for slightly different problem (Viridi, 2016).

As summary we can say that using the web you, as student can learn as deep as you wish and earlier than the class you are attending. Then you can ask the lecturer about materials that you do not understand.

Bolster D 2013CE30460: Fluid Mechanics Civil \& Environmental Engineering and Earth Sciences, University of Notre Dame, South Bend, Indiana https://www3.nd.edu/ bolster/Diogo_Bolster/Fluids.ht $\mathrm{ml}$

Chirgwin BH, Plumpton C 1967 Elementary Classical Hydrodynamics Oxford: Pergamon Press pp. 34-36 http://krishikosh.egranth.ac.in/bitstream/1/2030282/1/ 63822.pdf

Faber TE 2016 Fluid Mechanics Encyclopaedia Britannica https://www.britannica.com/science/fluidmechanics

Friedl S 2017 Fluids in Physics: Definition and Characteristics, Study.com http://study.com/academy/lesson/fluids-in-physicsdefinition-and-characteristics.html

Gibbs S 2016 How to Use Search Like a Pro: 10 Tips and Tricks for Google and Beyond the Guardian 15 Jan

https://www.theguardian.com/technology/2016/jan/15/ how-to-use-search-like-a-pro-10-tips-and-tricks-forgoogle-and-beyond

Gil P 2017 The Best Search Engines of 2017 LifeWire 29 Oct https://www.lifewire.com/best-search-engines2483352

Loney SL 1922 Mechanics and Hydrostatics for Beginners Cambridge: Univesity Press pp. 183-274 https://ia800704.us.archive.org/9/items/ost-physicsmechanicshydrost00loneuoft/mechanicshydrost00lone uoft.pdf

KeysToMaths 12013 Density, Buoyancy and Apparent Weight YouTube 28 Nov https://www.youtube.com/watch?v=mwV9i4jPEEA

KhanAcademy Fluids https://www.khanacademy.org/science/physics/fluids

Kuiper E, Volman M, Terwel J 2008 Infor. Res. 13351 http://www.informationr.net/ir/13-3/paper351.html

McDonough JM 2009Lectures in Elementary Fluid Dynamics: Physics, Mathematics and Applications, Departments of Engineering and Mathematics, University of Kentucky, Lexington https://www.engr.uky.edu/ acfd/me330-lctrs.pdf

Nave CR 2017 Fluids HyperPhysics http://hyperphysics.phy-astr.gsu.edu/hbase/fluid.html

Suarez A, Kahan S, Zavala G, Marti AC 2017 arXiv:1709.02313v2 https://arxiv.org/abs/1709.02313

van Biezen M 2016 Physics - Mechanics: Fluid Statics: Buoyance Force (6 of 9) Apparent Weight of a Submerged Object YouTube 9 Nov https://www.youtube.com/watch?v=YxYXSoj2wpU

Viridi S 2016 Tujuh Setengah Hari Fisika, Quantum Xcellensia, Surabaya, Indonesia, 3-6, 24-27 Mei p. 9 https://de.scribd.com/doc/313416567/Tujuh-SetengahHari-Fisika

YaleCourses 2008 20. Fluid Dynamics and Statics and Bernoulli's Equation YouTube 23 Sep https://www.youtube.com/watch?v=lfXDJKKPGfY 